\title{
Development and application of green and sustainable analytical methods for flavonoid extraction from Passiflora waste
}

\author{
Danielle da Silva Francischini ${ }^{1}$, Ana Paula Lopes ${ }^{1}$, Mateus Lodi Segatto ${ }^{1}$, Aylon Matheus Stahl ${ }^{1}$ \\ and Vânia Gomes Zuin ${ }^{1,2,3^{*}}$ (1)
}

\begin{abstract}
Brazilian biodiversity and favourable environmental conditions open up possibilities not yet explored, showing potential to shift the country's monochromatic economy into an emancipated, diversified and sustainable economic environment. This can be made possible through the integral use of its resources, exploring every functional fraction to create novel solutions to modern problems. Biorefineries present an interesting strategy to fully use the potential of agricultural feedstocks and together with green separation methods can contribute to the generation of sustainable processes and products. Passion Fruit (Passiflora edulis Sims f. flavicarpa Deg species) is produced on a large scale in Brazil and in other tropical countries, and its processing plants generate tons of residues that basically consist of peel, seeds and bagasse, which account for around $75 \%$ of its mass. These fractions of P. edulis can contain significant amounts of flavonoids, secondary metabolites that are the main compounds responsible for the fruit's bioactivity (antioxidant, anti-inflammatory, pesticide and biocide, in general). Therefore, this work aims to develop, apply and compare the best conditions for the extraction of isoorientin, orientin and isovitexin from passion fruit applying solidliquid methodologies, followed by analyte quantification using UHPLC-PDA. Homogenizer-assisted (HAE), ultrasoundassisted (UAE) and microwave-assisted (MAE) extraction techniques were used, as well as a full factorial design to reach optimal parameters concerning the extraction yield and energy and solvent efficiencies. According to the results, the procedure based on HAE presented the best conditions for the extraction of selected flavonoids (1.07, 0.90 and $0.33 \mathrm{mg} \mathrm{g}^{-1}$ of isoorientin, orientin and isovitexin, respectively) and was considered the best method according to the green and sustainable described factors.
\end{abstract}

Keywords: Green Analytical Chemistry, green extraction, Sustainable separation, Factorial design, Passiflora, Passion fruit, Food chain, Agro-industrial waste, Biorefinery, Flavonoids, UHPLC, Green Star

\section{Introduction}

Brazil has a great agricultural potential due to a major biodiversity and favourable environmental conditions that contribute to its agronomic development [1].

\footnotetext{
*Correspondence: vaniaz@ufscar.br; vania.zuin@york.ac.uk; vania. zuin@leuphana.de

1 Department of Chemistry, Federal University of São Carlos, São Carlos, São Paulo 15653-905, Brazil

Full list of author information is available at the end of the article
}

According to the Brazilian Institute of Geography and Statistics (IBGE), in 2018 agribusiness activity profits reached $R \$ 343.5$ billion, exceeding the value obtained in 2017 by $8.3 \%$ [2]. This raise is directly related to the growth in population and demand for food. However, this demand increases the production and consumption of processed aliments, consequently boosting the amount of waste generated by food processing. The United Nations Food and Agriculture Organization (FAO) estimated that one third of the food produced worldwide is lost or

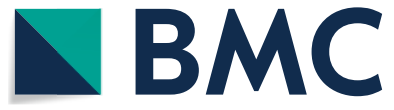

(c) The Author(s) 2020. This article is licensed under a Creative Commons Attribution 4.0 International License, which permits use, sharing, adaptation, distribution and reproduction in any medium or format, as long as you give appropriate credit to the original author(s) and the source, provide a link to the Creative Commons licence, and indicate if changes were made. The images or other third party material in this article are included in the article's Creative Commons licence, unless indicated otherwise in a credit line to the material. If material is not included in the article's Creative Commons licence and your intended use is not permitted by statutory regulation or exceeds the permitted use, you will need to obtain permission directly from the copyright holder. To view a copy of this licence, visit http://creativeco mmons.org/licenses/by/4.0/. The Creative Commons Public Domain Dedication waiver (http://creativecommons.org/publicdomain/ zero/1.0/) applies to the data made available in this article, unless otherwise stated in a credit line to the data. 
discarded per year [3]. Therefore, it is increasingly necessary to rethink society's lifestyle and encourage people to adopt processes which use products in their entirety, aiming at a more circular, sustainable future $[4,5]$.

Considering the processing steps in a food supply chain and reuse of biomass, as well as the principles of Green and Sustainable Chemistry and Green Analytical Chemistry, the biorefinery concept emerges as a sustainable alternative for transforming agro-industrial practices and laboratory activities in order to achieve sustainable processes [1]. In a conceptual waste biorefinery, the residue generated through human consumption, as well as the biomass lost or degraded in the retail and manufacturing stages of food production (bagasse, seeds and peels) is transformed into valuable co-products, which can range from fuels, platform chemicals, nutraceuticals and other high added value compounds [5-7].

Passion fruit is one of the most important fruits in Brazilian agriculture, which reached a production of 600,000 tons in 2018 [2]. The Passiflora (Passifloraceae family) genus has more than 500 species distributed in Latin America, of which 83 are present in Brazil. Passiflora edulis Sims $f$. flavicarpa Deg (yellow or sour passion fruit) and Passiflora alata (sweet passion fruit) are species of economic interest due to a large production of food products worldwide, especially juices and other beverages $[8,9]$. Nevertheless, while processing passion fruit, the peel, seeds and bagasse are considered as waste, although it is $75 \%$ of the fruit's mass [10]. This processing residue has significant amounts of oils, carotenoids, proteins, vitamins and phenolic compounds, such as flavonoids, that can be used to produce cosmetics, pharmaceuticals, pesticides and other fine chemical products $[8$, 11]. Thus, biomass transformation in a biorefinery platform allows an extended use of Passiflora fruits and also increases industrial competitiveness among the food supply chain $[12,13]$.

According to Freire [9], most of the research found in the literature for Passiflora aims at studying the chemical composition of its pulp and seed, with scarce studies that explore other parts of the passion fruit that are considered waste, such as the peels. Domínguez-Rodríguez et al. [14] also mentioned the lack of information about the phenolic profile of passion fruit peels and the importance of these samples for the extraction of antioxidant compounds. In the literature, it can also be observed that the focus of most studies is on the analysis of the antioxidant and antibacterial activities of Passiflora flavonoids $[14,15]$ and the nutritional composition of the fruit [16], having the sample preparation a supporting role in these studies.

Flavonoids are compounds that are used to produce food, drugs or cosmetics due to their anti-inflammatory, antioxidant and soothing effects $[17,18]$. They are a group of secondary metabolites with a basic molecular structure comprising 15 carbon atoms, represented by a C6-C3-C6 skeleton, in which two aromatic rings are linked through a three-carbon bridge, which is differentiated through substituent molecules (Fig. 1) [19]. Those found in the Passiflora species are of the C-glycoside type, which usually contain glucose as substituent molecules directly linked to the aromatic nucleus [17]. The flavonoids isoorientin and orientin can be found in the leaves and pulp of Passiflora species [18] and, together with isovitexin, in processing residues of the fruit (peels and seeds) [20-22], are the major compounds responsible for anti-inflammatory [23], antioxidant and antibacterial activities [20].

In the literature, studies that evaluated the efficiency of flavonoid extraction methods in passion fruit can be observed [8,14,24, 25], but there is scarcity in mentioning and/or applying Green Analytical Chemistry concepts within this context. Flavonoid extraction based on Green Analytical Chemistry intends to look for alternative and non-toxic solvents, increased energy efficiency and greater extraction yield, as well as reduced operation time, at a lower cost and aiming to mitigate the environmental impacts. Normally, the extraction step corresponds to $40 \%$ to $80 \%$ of the total cost of chemical processes [26-28]. Different extraction methods have been studied [27], in which solid-liquid extraction methods based on homogenizer-assisted (HAE), ultrasound-assisted (UAE) and microwave-assisted (MAE) extractions are used as sustainable methods to extract bioactive compounds from different types of plant material due to the possibility of using smaller volumes of greener solvents, lower sample mass and safety regarding the analyst [27, 29-31]. The analysis step, among other strategies, can benefit from miniaturization of analytical systems to reduce

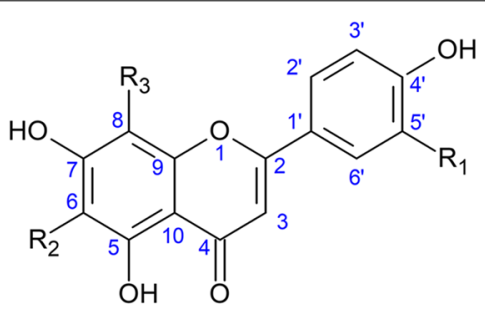

\begin{tabular}{r|c|c|c} 
& $\mathrm{R}_{1}$ & $\mathrm{R}_{2}$ & $\mathrm{R}_{3}$ \\
\hline Orientin & $\mathrm{OH}$ & $\mathrm{H}$ & glu \\
Isoorientin & $\mathrm{OH}$ & glu & $\mathrm{H}$ \\
Isovitexin & $\mathrm{H}$ & glu & $\mathrm{H}$
\end{tabular}

Fig. 1 Structure of flavonoids (Adapted from Zeraik [10]); glu, glucose 
its environmental impact. This can be seen in Liquid Chromatography systems, one of the most used methods to detect and quantify flavonoids, with the recent development of the Ultra High Performance Liquid Chromatography (UHPLC) technique, which due to a smaller column size and increased pressure can significantly reduce solvent use and analysis time without compromising selectivity and sensibility [32].

Although many analytical methodologies are often considered green and/or sustainable, rarely is there a proper assessment of comparable green and sustainable factors intrinsic to the developed processes. The literature describes different types of greenness assessment metrics that can be used to analyse and compare the green potential of any experiment, mainly comprising of quantitative metrics that measure direct chemical and material efficiency in synthetic chemistry (e.g. atom economy and E-factor) [33]. Recent advances have been reported on metrics specific to analytical chemistry, such as the National Environmental Method Index (NEMI) [34], Analytical Eco-Scale [35] and Green Analytical Procedure Index (GAPI) [36], which mainly focus on laboratory procedures. An adequate metric for sustainable chemistry assessment is the Life Cycle Assessment (LCA), which can evaluate whole systems by quantitative measurements on environmental, economic and social impacts from the material production, manufacturing, use and disposal $[33,37]$. The LCA is considered a complex metric because it requires all the inventory data, which may be a very time consuming and impracticable task, thus being replaced by less wholesome metrics [33].

In this study, the biorefinery concept alongside more benign extraction methods could be considered steps towards to more sustainable industrial scale processes but are unaccounted for in those typical green chemistry metrics [7, 38, 39]. By correlating experiment yield (in terms of mass of extracted compounds) with solvent and energy consumption, data can be obtained to analyse efficiency and sustainability aspects. This is an important approach to compare different extraction techniques and their scalability, which is a simpler and more holistic appraisal.

Therefore, the present work sought to integrate the biorefinery concepts when establishing methods for extracting bioactive compounds from Passiflora edulis fo. flavicarpa (yellow passion fruit) peel, from a conventional farming model considering the principles of Green Analytical Chemistry [40]. Methods based on renewable solvents to extract orientin, isoorientin, isovitexin were developed, optimised and applied, as well as the development of the analytical method to detect and quantify these compounds using a UHPLC-PDA-QDa system. To evaluate the green and sustainable aspects, different comparison approaches were adopted to estimate energy and solvent volume efficiency for each extraction method.

\section{Methods \\ Sample conditioning}

The passion fruit samples were acquired from the city of São Carlos, São Paulo state, Brazil, in a local market. The collection and handling of the plant material were performed with compliance with institutional and national guidelines, including the register at the Brazilian National Management System of the Genetic Patrimony and Associated Traditional Knowledge (SisGen), register code A4C7EC8. Approximately 30 pieces of fruit were peeled, separating the yellow shell (mesocarp) from the white interior (epicarp). The yellow peels were dried in an air circulation oven for 7 days at $35{ }^{\circ} \mathrm{C}$, initially blended in a domestic blender, followed by milling in an analytical mill and sieved to obtain particle sizes smaller than 60 mesh.

\section{Chemicals and reagents}

The analytical standards of the flavonoids isoorientin and orientin were purchased from Sigma-Aldrich ${ }^{\circledR}$ (assay $\geq 95 \%$, São Paulo, SP, Brazil) and isovitexin from HWI Pharma Solutions (assay $\geq 90.38 \%$, Rülzheim, Germany). For the extraction of flavonoids in the passion fruit peel, ethanol (HPLC grade, Panreac ${ }^{\circledR}$, Barcelona, Spain) and distilled water were used. In the chromatographic separation, acetonitrile (HPLC grade from Tedia, Fairfield, US), methanol (HPLC grade from Honeywell, Charlotte, North Caroline, US), ultrapure water (MiliQ system from Millipore ${ }^{\circledR}$, Burlington, US) and formic acid (Sigma-Aldrich, São Paulo, Brazil, assay $\geq 95 \%$ ) were used.

\section{Extraction techniques and factorial design}

Factorial designs were applied for each extraction technique. Table 1 summarizes the variables and their levels which were studied for HAE, UAE and MAE experiments, as can be seen below. Details for each technique are found in the following topics.

\section{Homogenizer assisted extraction (HAE)}

The HAE extraction was performed by IKA's T10 basic Ultra-Turrax $^{\circledR}$ (Staufen im Breisgau, Germany) mixer. The dried sample was weighed with an analytical balance and transferred to a $15 \mathrm{~mL}$ falcon tube, followed by the addition of $5 \mathrm{~mL}$ of the solvent and extraction using the mixer at a fixed rotation of $15.360 \mathrm{rpm}$ for a variable time, according to the factorial design. A complete factorial design $2^{3}$ was developed in which the variables' sample/solvent ratio, time and concentration of ethanol in 
Table 1 Experimental variables for the different extraction methods studied

\begin{tabular}{llllll}
\hline $\begin{array}{l}\text { Extraction } \\
\text { method }\end{array}$ & Variables & Unit & \multicolumn{3}{l}{ Levels } \\
\cline { 3 - 6 } & & & $\mathbf{- 1}$ & $\mathbf{0}$ & $\mathbf{1}$ \\
\hline HAE & Sample/Solvent ratio & - & 0.05 & - & 0.1 \\
& EtOH/ $\mathrm{H}_{2} \mathrm{O}$ & $\%$ & 30 & - & 70 \\
& Time & Min & 2 & - & 8 \\
UAE & Sample/Solvent ratio & - & 0.05 & 0.07 & 0.1 \\
& EtOH/ $/ H_{2} \mathrm{O}$ & $\%$ & 30 & 50 & 70 \\
& Time & Min & 15 & 38 & 60 \\
MAE & Sample/Solvent ratio & - & 0.05 & 0.07 & 0.1 \\
& EtOH/ $\mathrm{H}_{2} \mathrm{O}$ & $\%$ & 30 & 40 & 50 \\
& Time & Min & 5 & 15 & 25 \\
& Temperature & ${ }^{\circ} \mathrm{C}$ & 60 & 90 & 120 \\
\hline
\end{tabular}

water were evaluated, thus resulting in 8 experiments. In order to evaluate the relative standard deviation (SD) and the reproducibility of the extraction method, replicates were performed in three different experiments.

\section{Ultrasound assisted extraction (UAE)}

The UAE was performed using Ultrasonic Cleaning, Soni-Tech TDRFORCE ${ }^{\circledR}$ (São Bernardo dos Campos, Brazil) equipment with fixed power at $125 \mathrm{~W}$. The samples were weighed, according to the sample/solvent ratio, and added to a $25 \mathrm{~mL}$ glass tube with a fixed volume of $5 \mathrm{~mL}$ of the solvent, which was placed in the ultrasonic bath and followed by extraction. A complete factorial design $2^{3}$ with a central point was applied resulting in 9 experiments. The central point experiment was performed in triplicate in order to assess the relative standard deviation and the reproducibility of the extraction method. The evaluated variables were sample/solvent ratio, time and concentration of ethanol in water.

\section{Microwave assisted extraction (MAE)}

The MAE extraction method was performed by Berghof-Speedwave ${ }^{\circledR} \quad$ (Baden-Württemberg, Germany) equipment, with a fixed power of $800 \mathrm{~W}$ and 30 bars of maximum pressure. The procedure started by weighing the dried samples on an analytical balance and adding it to the microwave flask with $7 \mathrm{~mL}$ of the solvent, which was placed inside the microwave oven. The heating started with a ramp from $30^{\circ} \mathrm{C}$ to the desired temperature, which remained constant for the time selected for each experiment. To carry out the experiments, a 24 experimental design with a central point was developed, thus resulting in 17 experiments, considering the central point to be performed in quadruplicate in order to assess the relative standard deviation and the reproducibility of the method. The variables studied were the sample/solvent ratio, time, temperature and concentration of ethanol in water.

\section{Multivariable analysis}

In order to assess the importance of the variables chosen in the studied extraction methods, complete factorial designs were used for each experiment (please check Additional file 1: Tables S1-S3). Thus, the influence of each variable (primary effects) and the influence of the interaction between variables (secondary effects) were calculated and the effect graph was obtained. The values obtained in concentration per mass of sample $\left(\mathrm{mg} \mathrm{g}^{-1}\right)$ of each flavonoid were multiplied by the coded value of the factorial design $(-1,0$ or +1$)$ for each variable analysed and summed up, obtaining the effect values (E). Thus, the ratio between the squared effect $\left(\mathrm{E}^{2}\right)$ values and the sum of the squared effects represents the percentage that each variable influences the extraction yield, which can be found in Additional file 2 for all three techniques.

\section{Analysis and quantification of flavonoids by UHPLC-PDA}

The quantitative analysis of the flavonoids was performed using the Ultra High Performance Liquid Chromatography (UHPLC) system Waters ACQUITY H-class UPLC ${ }^{\circledR}$ (Milford, US), coupled with Photodiode Array UV (PDA) and QDa mass spectrometer detectors, in which the instrumental parameters as the composition of mobile phase and the composition gradient, the column, flow rate and temperature were previously optimised in order to obtained analytical signal with high resolution. The mobile phase consisted of ultrapure water acidified with $0.1 \%$ formic acid (A) and acetonitrile (B). The extracts were centrifuged at $20^{\circ} \mathrm{C}(10,000 \mathrm{rpm})$ for $20 \mathrm{~min}$ and the supernatant was filtered through a $20 \mu \mathrm{m}$ PTFE membrane, followed by an injection of $1 \mu \mathrm{L}$ of the resulting solution. The stationary phase used was the ACQUITY HSS C18 SB column (Waters, Milford, MA, US, $1.8 \mu \mathrm{m}$; $2.1 \times 100 \mathrm{~mm}$ ) at $40{ }^{\circ} \mathrm{C}$. The elution occurred in a gradient mode with a flow rate of $0.3 \mathrm{~mL} \cdot \mathrm{min}^{-1}$, starting with $10 \%$ of $\mathrm{B}$ and reaching $100 \%$ of B in a 25 -min gradient. The chromatograms were recorded in a fixed wavelength of $330 \mathrm{~nm}$. For each flavonoid, an analytical curve was prepared in methanol in five different concentrations: 10 , 20, 40, 60, 80 and $100 \mathrm{mg} \mathrm{L}^{-1}$ and stored at $4^{\circ} \mathrm{C}$.

\section{Figures of merit}

To carry out the validation of the analytical method, the parameters Specificity, Linearity, Recovery, Precision and the Limits of Detection (LOD) and Quantification (LOQ) were evaluated in accordance with the International Council for Harmonization (ICH) standard [41]. 
To assess specificity, the UV-Vis and mass spectra of each flavonoid obtained at three different retention times at a wavelength of $350 \mathrm{~nm}$ were compared. For orientin, the retention times were 5.097, 5.114 and $5.048 \mathrm{~min}$, for isoorientin 5.309, 5.292 and $5.424 \mathrm{~min}$ and for isovitexin $6.365,6.408$ and $6.333 \mathrm{~min}$. The linearity was studied from the correlation coefficient $\left(R^{2}>0.99\right)$, and the values of LOD and LOQ were calculated from the analytical curve, according to the $\mathrm{ICH}$ guidelines. To evaluate the steps of recovery and precision (intra-day) three extractions of passion fruit sample were carried out with $400 \mu \mathrm{L}$ of standard solution in different concentrations, obtaining the final concentrations of $10,20,40 \mathrm{mg} \mathrm{L}^{-1}$ of orientin, isoorientin and isovitexin.

\section{Green and sustainable factors}

Besides the concentration per mass of sample, three other parameters were calculated in order to evaluate green and sustainable factors and industrial feasibility for all extraction methods: sample mass, energy and solvent volume efficiency. These were obtained based on the final mass of the analytes for each experiment by calculating the amount of each parameter consumed per mass of analyte extracted. The energy spent (watt-hour) on each experiment was determined by multiplying the equipment's power (watts) by the total extraction time (hours), while sample mass and solvent volume were determined by the factorial design. Each efficiency was calculated by dividing the values of energy $(\mathrm{kWh})$, sample mass $(\mathrm{kg})$ and solvent consumption (L) by the value of mass (in $\mathrm{g}$ ) of the analyte for each experiment.

\section{Results and discussion}

\section{Calibration curve and figures of merit}

The parameters regarding the validation of the calibration curve showed an acceptable correlation coefficient $\left(\mathrm{R}^{2}>0.99\right)$, as well as LOD and LOQ consistent with the extraction yields. Table 2 summarizes the validation data for each analyte. Recovery essays in the best extraction technique resulted in values from 89.5 to $99.35 \%$, which are inside the acceptable values for most validation guidelines (80-120\%). Intra-day error, as represented by the variation coefficient, showed errors from 0.22 to $3.86 \%$, a good range that represents low fluctuations in the peak area values within the same day of analysis. Specificity was evaluated using the UV-profile in three retention times within a peak and QDa $\mathrm{m} / \mathrm{z}$ values for each peak in extracts from all extraction techniques. The UV and QDa profiles of standards compounds and their related peaks in the extracts can be seen in Additional file 3, and the chromatograms for each extraction method are presented in the next sections. Acceptable peak purity can be observed for the proposed analytes considering both criteria.

\section{Homogenizer assisted extraction (HAE)}

Following the analytical procedure and chromatographic method describe in session 2.4 , the chromatography profile of $P$. edulis extract was obtained, as can been seen in Fig. 2, in which each analyte could be detected and efficiently separated. The experimental design described for each extraction methodology were used and the responses were obtained using the extraction yield in $\mathrm{mg}$

Table 2 Calibration curves for orientin, isoorientin and isovitexin and linearity parameters

\begin{tabular}{|c|c|c|c|c|c|c|}
\hline Compound & Equation & $\mathbf{R}^{2}$ & $\operatorname{LOD}\left(\mathrm{mg} \mathrm{L}^{-1}\right)$ & $\mathrm{LOQ}\left(\mathrm{mg} \mathrm{L}^{-1}\right)$ & Recovery (\%) & Intra-day error (\%) \\
\hline Orientin & $y=6637.2 x-45232$ & 0.9951 & 4.28 & 14.27 & $97.40-99.35$ & $0.22-2.15$ \\
\hline Isoorientin & $y=8188.1 x+13382$ & 0.9995 & 2.00 & 6.65 & $96.49-99.35$ & $0.34-1.52$ \\
\hline Isovitexin & $y=8210.9 x+22235$ & 0.9994 & 0.90 & 2.90 & $89.50-95.72$ & $1058-3.86$ \\
\hline
\end{tabular}

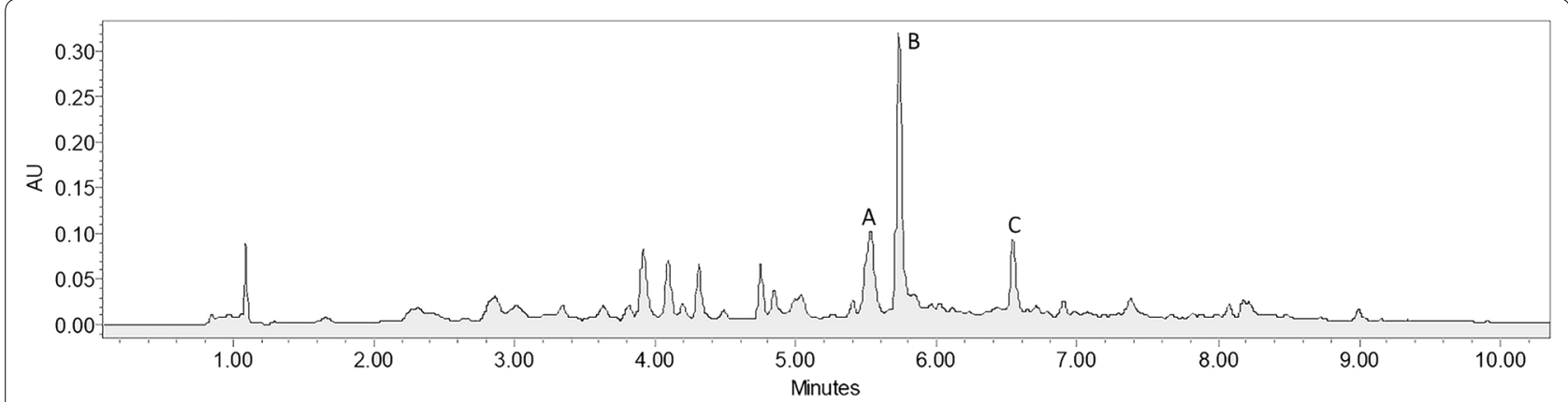

Fig. 2 Chromatography profile of P. edulis alcoholic extract, obtained from HAE, with the following analytes: (a) orientin, (b) isoorientin and (c) isovitexin 
of analyte per gram of sample. The results for extraction using the HAE method, as well as its factorial design, are shown in Additional file 1: S1. The conditions used in experiment 8 (all variables in maximum level, +1 ) showed the best yield for all analytes, with isoorientin at a higher concentration than the other analytes (1.11 $\mathrm{mg} \mathrm{g}^{-1}$ ).

Multivariate analysis was carried out by calculating the influence of each variable (primary effects) and the influence of the interaction between variables (secondary effects) in the final response. Figure 3 shows the calculated effects in $\mathrm{mg} \mathrm{g}^{-1}$ for the extractions with HAE, as ruled by the variables 1 (sample/solvent ratio), 2 (ethanol/water concentration) and 3 (extraction time). For all three analytes, variable 2 had a major positive influence on the final response, accounting for $92 \%$ of the effects for isoorientin and 91\% for both orientin and isovitexin.

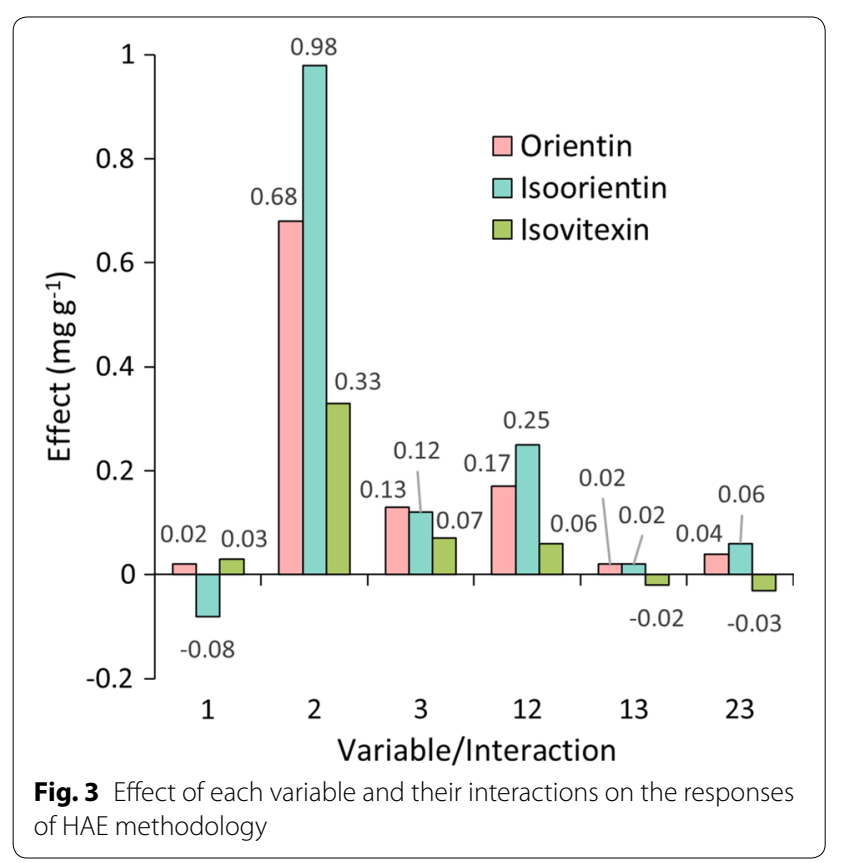

This means that a higher percentage of ethanol in water was mainly responsible for improving the extraction yield for all analysed compounds, considering the range selected for HAE $\left(30-70 \%\right.$ of EtOH $\left./ \mathrm{H}_{2} \mathrm{O}\right)$. This can be seen in the responses from experiments 3,4 and 7 (Additional file 1: S1), in which the variations between their responses and the experiment with the highest yield (8) are less than $10 \%$. Most of the other variables and their interactions showed slightly positive effects, although low percentual values, meaning that their influence is small or not significant to the response. Such observations can lead us to conclude that the solubility change when varying the percentage of ethanol in water has a higher effect than the other parameters studied in this extraction technique, proving to be a key aspect regarding HAE methodologies. In this case, all three analytes have shown better extraction yields in a $70 \%$ solution of ethanol in water.

\section{Ultrasound assisted extraction (UAE)}

The chromatography profile of $P$. edulis extract can be seen in the Fig. 4, in which is possible to observe that the signal intensity of the analytes in UAE method were lower compared to HAE extraction. Results from UAE (Additional file 1: S2) showed similar extraction yields for orientin and isoorientin, which both peaked in experiments 1 and 5, although at lower levels than in HAE experiments. Isovitexin has also been found in lower levels, reaching up to 0.17 and $0.18 \mathrm{mg} \mathrm{g}^{-1}$ in experiments 1 and 5 , respectively.

According to the analysis of the effects of each parameter in UAE (Fig. 5), variables 1 (sample/solvent ratio) and 2 (concentration of ethanol in water) had higher negative effects on the response for all three compounds. Sample/ solvent ratio accounted for $87 \%, 93 \%$ and $86 \%$ of the total effect for orientin, isoorientin and isovitexin, respectively. Due to a negative effect, a higher response is found when a smaller sample/solvent ratio is used, i.e. a higher volume of solvent per mass of sample. Ethanol concentration

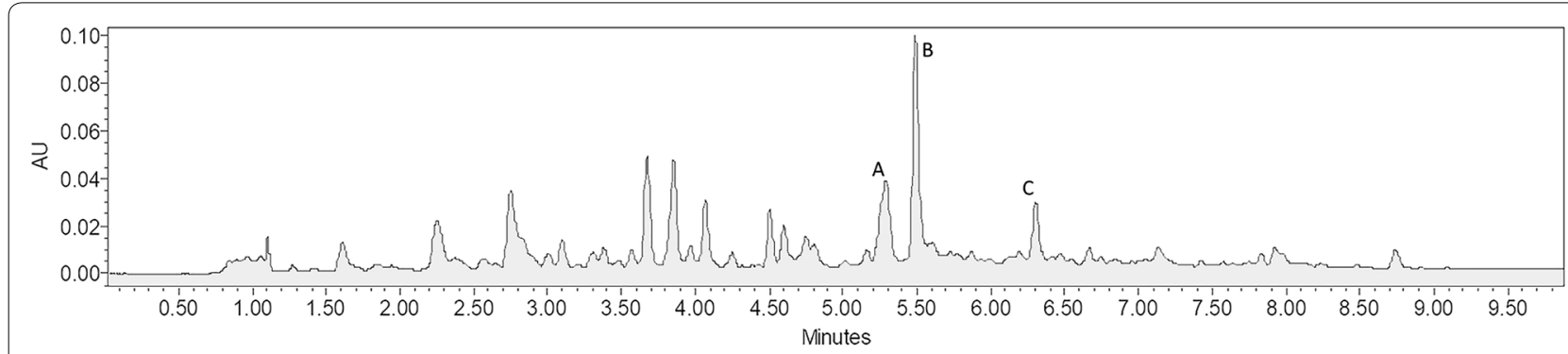

Fig. 4 Chromatography profile of P. edulis alcoholic extract, obtained from UAE, with the following analytes: (a) orientin, (b) isoorientin and (c) isovitexin 


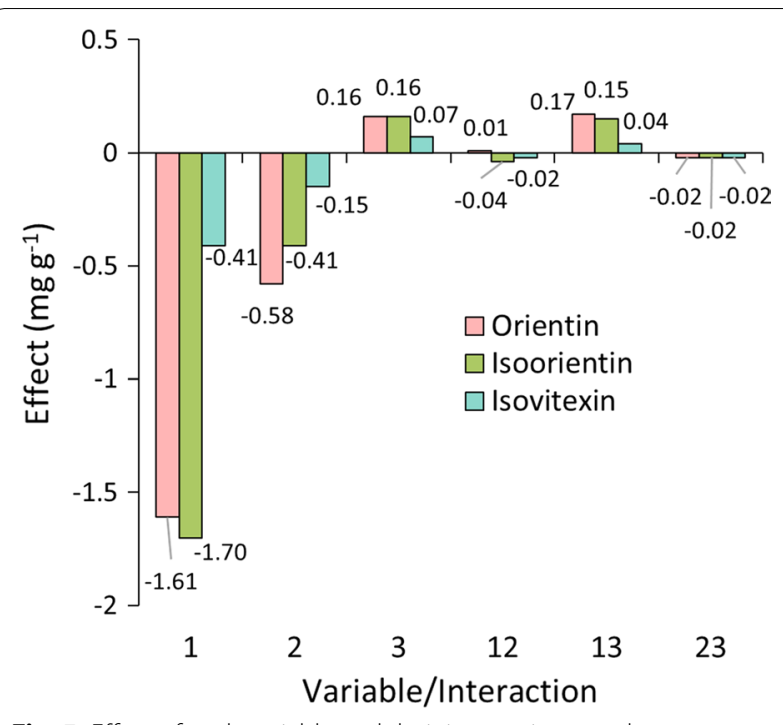

Fig. 5 Effect of each variable and their interactions on the responses of UAE methodology

in water, although showing effects no higher than $11 \%$, negatively affected the response, which means that a smaller $\% \mathrm{EtOH} / \mathrm{H}_{2} \mathrm{O}$ is preferable in this condition. Experiments with higher extraction yields (1 and 5) were performed with both variables 1 and 2 at lower levels, although experiment 1 may be preferable due to a lower time, and therefore a lower energy consumption.

\section{Microwave assisted extraction (MAE)}

The Fig. 6 presents the chromatography profile of $P$. edulis extract and can be seen that the analytical signal of all three analytes were similar compared to HAE, although with slightly lower yields (Additional file 1: S3). Higher concentrations of orientin were obtained in experiments $17\left(0.89 \mathrm{mg} \mathrm{g}^{-1}\right), 9\left(0.88 \mathrm{mg} \mathrm{g}^{-1}\right)$ and experiments 10 and $2\left(0.82 \mathrm{mg} \mathrm{g}^{-1}\right)$. Experiment 10 was the most successful in terms of extracting isoorientin (0.94 $\left.\mathrm{mg} \mathrm{g}^{-1}\right)$ and isovitexin $\left(0.34 \mathrm{mg} \mathrm{g}^{-1}\right)$, followed by experiments 5,17 and 9, showing a more complex influence of the variables in the final results, as will be discussed below.

It can be observed in Fig. 7 that the interaction between variables 1 (sample solvent) and 4 (temperature) had a major positive effect on the extraction of orientin and isoorientin, with an influence of 19.2 and $24.5 \%$, respectively. This means that when both variables were at a maximum level, a higher extraction yield was observed. This is closely followed by the effects of variable 3 (extraction time), which had a negative impact of $17.5 \%$ for orientin and $22.3 \%$ for isoorientin, meaning that higher responses were obtained from the experiments with variable 3 in the lower level. Isovitexin, on the other hand, was mostly influenced by variable 4 (temperature), responsible for $26.1 \%$ (positively) of the total effect for this analyte. Therefore, experiments 17 (all variables in central point) and 10 (variables 1 and 4 in higher levels and variables 2 and 3 in lower levels) showed the highest extraction yields, in which experiment 10 yielded slightly better for isoorientin and isovitexin.

\section{Comparative assessment \\ Extraction yield}

To compare the extraction methods, experiment 8 from HAE, experiment 1 from UAE and experiment 10 from MAE were selected due to their optimal yield, in terms of concentration of analyte per mass of sample, as can be seen in Table 3. HAE presented the best results for flavonoid concentration. Comparing it to MAE, orientin and isoorientin values are $12.7 \%$ and $15.3 \%$ higher, respectively, and isovitexin extraction yields were equal. Moreover, the homogenizer-assisted technique presented higher concentrations than UAE, which were $25.5 \%, 38.7 \%$ and $50 \%$ higher for orientin, isoorientin and isovitexin, respectively.

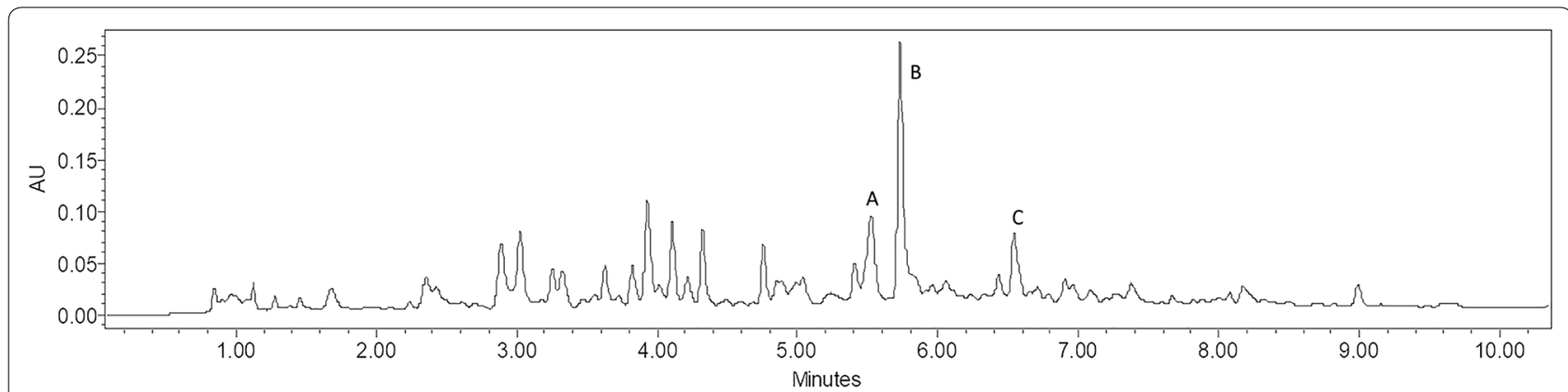

Fig. 6 Chromatography profile of P. edulis alcoholic extract, obtained from MAE, with the following analytes: (a) orientin, (b) isoorientin and (c) isovitexin 


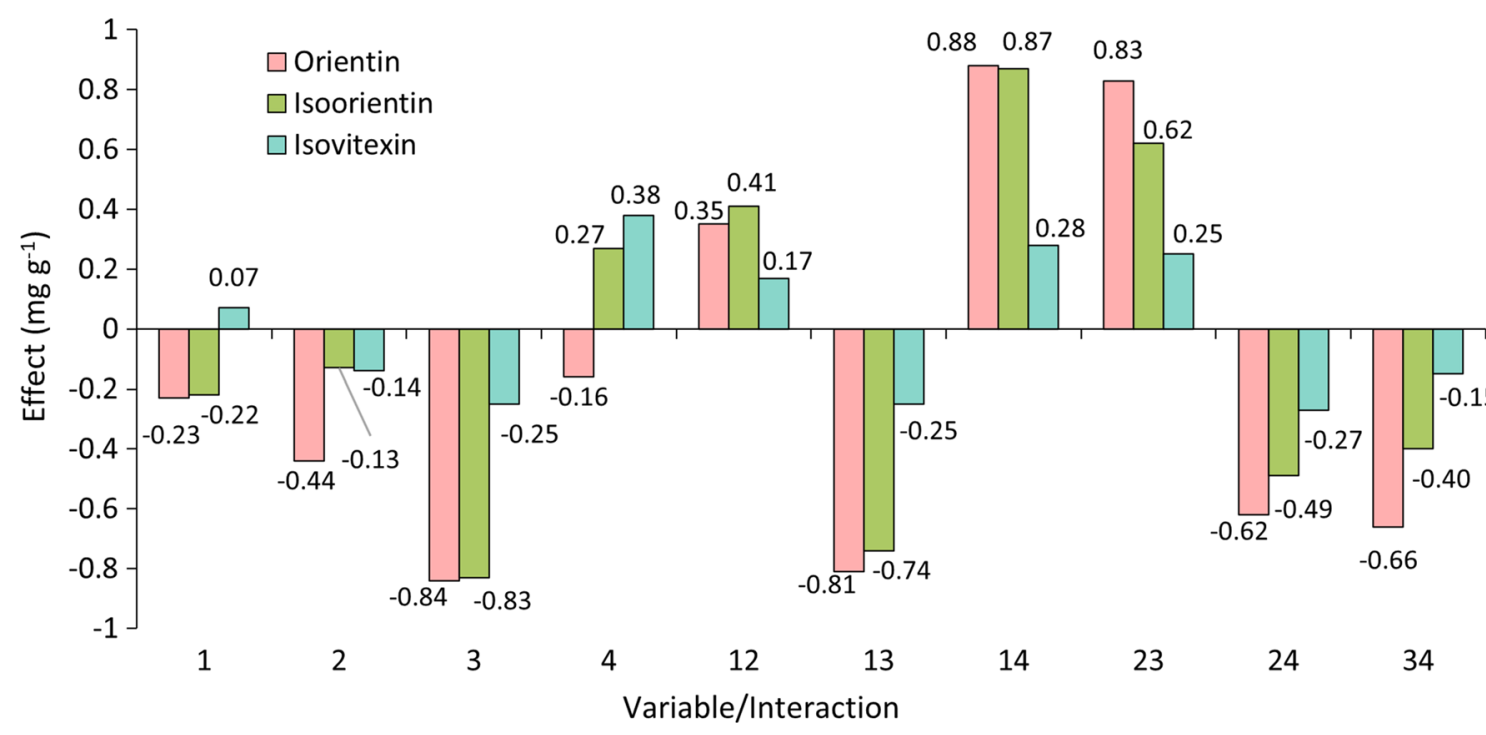

Fig. 7 Effect of each variable and their interactions on the responses of MAE methodology

Table 3 Comparison between experimental yields of each extraction methods

\begin{tabular}{llll}
\hline $\begin{array}{l}\text { Extraction } \\
\text { method }\end{array}$ & \multicolumn{2}{l}{ Experimental yield } \\
\cline { 2 - 4 } & $\mathbf{m g ~ g}^{-\mathbf{1}}$ & \\
\cline { 2 - 4 } & Orientin & Isoorientin & Isovitexin \\
\hline HAE & 0.94 & 1.11 & 0.34 \\
UAE & 0.70 & 0.68 & 0.17 \\
MAE & 0.82 & 0.94 & 0.34 \\
\hline
\end{tabular}

\section{Green and sustainable factors}

In order to evaluate green and sustainable factors and estimate the possible scalability, the amount of sample $\left(\mathrm{kg} \mathrm{g}^{-1}\right)$, energy $\left(\mathrm{kWh} \mathrm{g}^{-1}\right)$ and solvent $\left(\mathrm{L} \mathrm{g}^{-1}\right)$ required to extract $1 \mathrm{~g}$ of each analyte was calculated. For each extraction method, experiments that show a variation of up to $10 \%$ in relation to the highest extraction yield ( $\mathrm{mg} \mathrm{g}^{-1}$ of sample) were compared. The results for all selected experiments can be seen in Additional file 4.

For the HAE method, experiments 8, 3, 4 and 7 were selected for analysis. When comparing the results obtained, it can be observed that experiment 4 presents the best values for sustainable factors and requires, on average, $74 \%$ less energy when compared to experiment 8 , although the latter demands $4 \%$ less solvent and slightly less sample mass to extract $1 \mathrm{~g}$ of each analyte (3\%). In the UAE method, experiments 1 and 5 were selected, and the calculated factors show that experiment 1 requires on average $74 \%$ less energy than experiment 5 , but $3 \%$ more solvent volume and sample mass. Regarding the MAE methodology, experiment 10 and 17 were selected, and from the results, it can be noted that experiment 10 requires $77 \%$ less energy, 33\% less solvent volume and $6 \%$ less sample mass to extract $1 \mathrm{~g}$ of the analytes, on average.

As can be seen in Fig. 8, the comparison of three methods concerning sustainable factors also lead to HAE (experiment 4) being the most environmentally safe among the techniques, consuming approximately 91\% and $95 \%$ less energy on average than MAE (experiment 10) and UAE (experiment 1), respectively. Furthermore, the Homogenizer-based method had an average of $71 \%$ less solvent consumption than UAE and 3\% less than MAE, while keeping a good ratio of extraction per mass of sample, as discussed in Sect. "Extraction yield".

\section{Discussion}

The HAE has been described in some works due to its low cost, time and energy consumption for phenolic compound extraction from plant materials such as banana passion fruit [42], honeysuckle flowers [43], seeds and other plant materials of berry fruit [44]. The mechanism behind the HAE method involves solvent diffusion into the cell through mechanical rupture caused by high-performance agitation, extracting the compounds [43]. In UAE, the extracting mechanism occurs by interaction between the cell wall and ultrasound waves, which promotes cell rupture and solvent diffusion. The extracting phenomenon for MAE is similar to UAE, except it applies thermic waves instead of ultrasounds waves. The difference between MAE and other heating mechanisms are the heat exchange directions, which also occurs from the inside of cells to the outside due to 


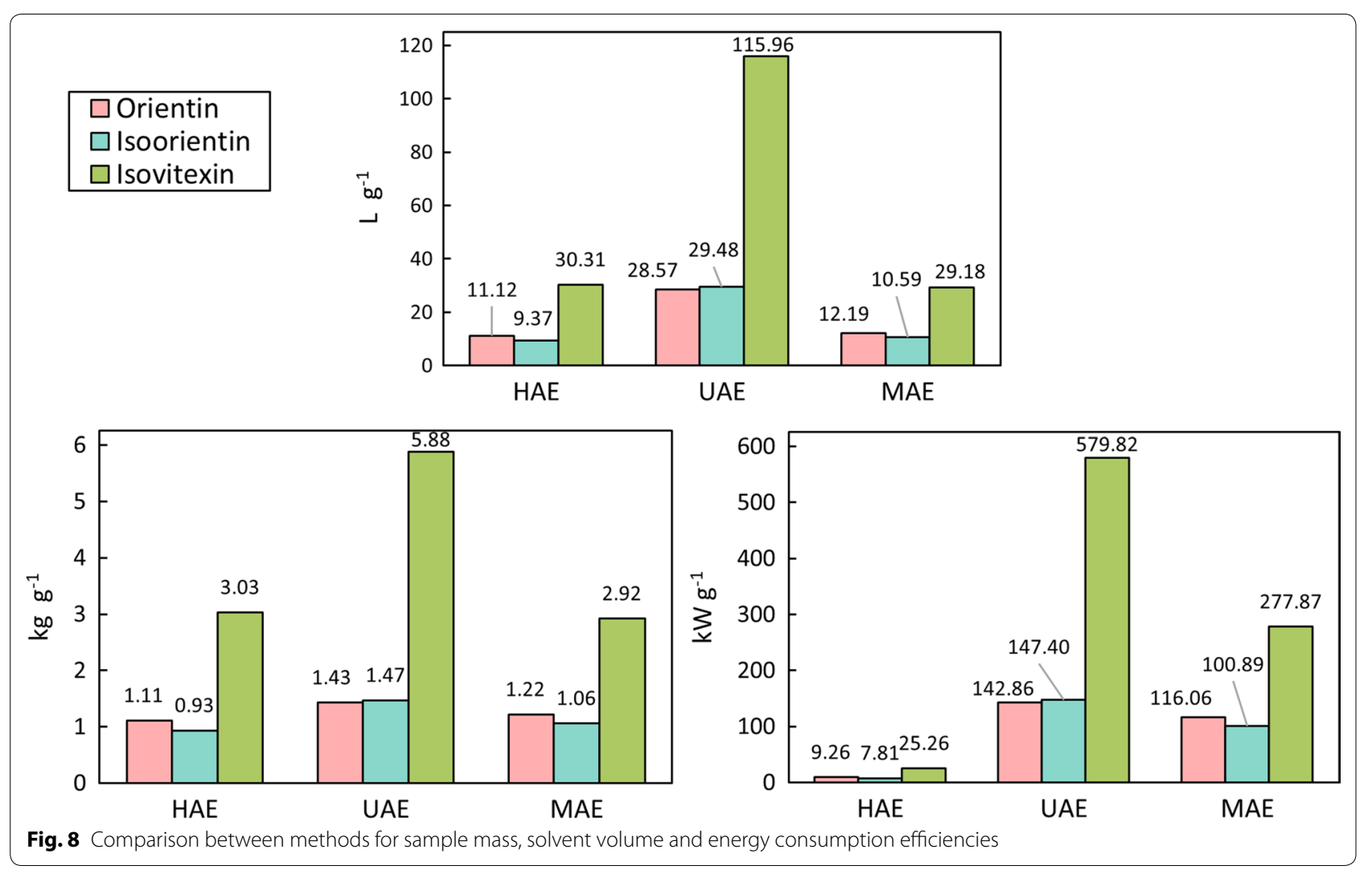

the microwave radiation, enhancing cell rupture and the release of the analytes [30, 45, 46]. MAE and UAE techniques are promising alternatives for flavonoid study in plant matrixes such as passion fruit. This is supported by the comparable results of these extraction methods with HAE. However, according to Vinatoru et al. and Zhang et al. [30, 47], due to their sound or thermic waves-based phenomenon, degradation of phenolic compounds may occur with long sonication time or high microwave temperatures, thus decreasing the extraction yield.

It is important to observe that assessing factors related to sustainability and scalability in lab scale extraction methodologies, as energy and solvent volume efficiency, could be essential to help evaluate best parameters and comparing as well applying different techniques [48, 49]. The case of experiments 4 and 8 from HAE, for example, showed that although very comparable extraction yields (mg.g $\mathrm{g}^{-1}$-which is usually the most assessed response in extractions of natural products-experiment 4 was chosen to be superior due to a higher energy efficiency. An analogous conclusion was observed in the comparison between HAE and MAE selected experiments, which had similar performances considering the concentration and solvent volume efficiency, but MAE showed to require more energy than HAE in this study. Such factors can help us distinguish efficiency in terms of mass yield and in terms of energy and solvent consumption, helping us to better understand true sustainability for each technique and to make a fairer comparison of green technologies. In this case, we concluded that two extraction techniques (MAE and UAE) that are usually listed as green and/or sustainable methods, had lower energy and solvent efficiencies than HAE, which is usually neglected as a sustainable technology for the extraction of natural products.

\section{Conclusion}

The integration of biorefinery concepts and green analytical techniques were investigated in this case study. By applying more benign extraction techniques such as HAE, UAE, MAE, using renewable solvents and performing a factorial design, more sustainable separation methods were developed, optimised and applied aiming at obtaining value-added bioactive compounds such as orientin, isoorientin and isovitexin from Brazilian passion fruit waste. The comparison of the quantitative results obtained by UHPLC-PDA showed HAE as the one with better extraction yields and lowest energy consumption in optimum parameters of 0.1 sample/solvent ratio, $70 \%$ solution of ethanol in water and 2 min of extraction. 
Presenting the best extraction yield, energy and solvent efficiencies, HAE has shown to be the greenest and most efficient method among the studied methods. The combination of these findings can help us to understand the different extraction techniques and their relevant variables, as well as taking a further step into a feasible passion fruit waste sustainable biorefinery, by using scalable processes, boosting circular economy in the food supply chain.

\section{Supplementary information}

Supplementary information accompanies this paper at https://doi. org/10.1186/s13065-020-00710-5.

\section{Additional file 1: Normalized effects for variables from all three extraction} techniques.

Additional file 2: UV profile and QDA data of extracts from all three extraction techniques

Additional file 3: Experimental design and responses for orientin, isoorientin and isovitexin from all three extraction techniques.

Additional file 4: Results of green and sustainable factors from all three extraction techniques.

\section{Abbreviations}

P. edulis: Passiflora edulis; HAE: Homogenizer-assisted extraction; UAE: Ultrasound-assisted extraction; MAE: Microwave-assisted extraction; IBGE: Brazilian Institute of Geography and Statistics; FAO: Food and Agriculture Organization; UHPLC: Ultra High Performance Liquid Chromatography; PDA: Photodiode Array; QDa: Mass spectrometer detectors; UV: Ultraviolet radiation; NEMI: National Environmental Method Index; GAPI: Green Analytical Procedure Index; LCA: Life Cycle Assessment; SD: Standard deviation; E: Squared effects; LOD: Limits of detection; LOQ: Limits of quantification; ICH: International Council for Harmonization; R: Correlation coefficient; EtOH: Ethanol; $\mathrm{H}_{2} \mathrm{O}$ : Water.

\section{Acknowledgements}

The authors are grateful to the Applied Instrumental Analysis Group (UFSCar SP, Brazil), especially to Prof. Joaquim Nóbrega and Dr. Lucimar Fialho, for allowing us to perform the microwave experiments in their laboratory.

\section{Authors' contributions}

DSF and APL performed the experiments and wrote the manuscript. MLS and AMS designed the figures and wrote the manuscript. VGZ was coordinator and advisor in this work and wrote the manuscript. All authors read and approved the final manuscript.

\section{Funding}

This work was financial supported by the São Paulo Research Foundation (Fapesp) Brazil (2017/05712-0, 2018/11409-0 and 2017/25015-1) and by the Coordination for the Improvement of Higher Education Personnel (Capes), Brazil (001/1622968)

\section{Availability of data and materials}

The datasets supporting the conclusions of this article are included within the article and its Additional files 1, 2, 3, 4 .

\section{Ethics approval and consent to participate}

Not applicable.

\section{Consent for publication}

Not applicable.

\section{Competing interests}

The authors declare that they have no competing interests. The funders had no role in the design of the study; in the collection, analyses, or interpretation of data; in the writing of the manuscript, or in the decision to publish the results.

\section{Author details}

${ }^{1}$ Department of Chemistry, Federal University of São Carlos, São Carlos, São Paulo 15653-905, Brazil. ${ }^{2}$ Green Chemistry Centre of Excellence, University of York, North Yorkshire YO10 5DD, UK. ${ }^{3}$ Institute of Sustainable and Environmental Chemistry, Leuphana University, Universitätsallee 1, C13, 13352 Lüneburg, Germany.

Received: 22 June 2020 Accepted: 10 September 2020

Published online: 18 September 2020

\section{References}

1. Perlatti B, Forim MR, Zuin VG (2014) Green chemistry, sustainable agriculture and processing systems: a Brazilian overview. Chem Biol Technol Agric 1:1-9

2. $\quad$ IBGE (2018) Produção Agrícola Municipal (PAM) 2018

3. Directorate-General for Environment (European Commission) (2012) European Commission Preparatory Study on Food Waste Across EU-27. https://doi.org/10.2779/85947

4. Kümmerer K, Clark JH, Zuin VG (2020) Rethinking chemistry for a circular economy. Science 367:369-370

5. Zuin VG (2016) Circularity in green chemical products, processes and services: innovative routes based on integrated eco-design and solution systems. Curr Opin Green Sustain Chem 2:40-44

6. Alvim JC, Alvim FALS, Sales VHG et al (2014) Biorrefinarias: conceitos, classificação, matérias primas e produtos. J Bioen Food Sci J Bioenergy Food Sci Macapá 1:61-77

7. Rodrigues JAR (2011) Do engenho à biorrefinaria. A usina de açúcar como empreendimento industrial para a geraçãi de produtos bioquímicos e biocombustíveis. Quim Nova 34:1242-1254

8. Gomes SVF, Portugal LA, dos Anjos JP, de Jesus ON, de Oliveira EJ, David JP, David JM (2017) Accelerated solvent extraction of phenolic compounds exploiting a Box-Behnken design and quantification of five flavonoids by HPLC-DAD in Passiflora species. Microchem J 132:28-35

9. Freire VF (2017) Estudo dos alcaloides $\beta$-carbolínicos dos frutos de Passiflora alata e de Passiflora edulis utilizando SBSE. Diss. Mestrado, Inst. Química São Carlos, Univ. São Paulo, São Carlos, LC/Flu e LC/MS

10. Arvanitoyannis IS, Varzakas TH (2008) Fruit/Fruit juice waste management: treatment methods treated waste. In: Waste Manag. Food Ind. Elsevier Inc., pp 569-628

11. Kandandapani S, Balaraman AK, Ahamed HN (2015) Extracts of passion fruit peel and seed of Passiflora edulis (Passifloraceae) attenuate oxidative stress in diabetic rats. Chin J Nat Med 13:680-686

12. Pfaltzgraff LA, De Bruyn M, Cooper EC, Budarin V, Clark JH (2013) Food waste biomass: a resource for high-value chemicals. Green Chem 15:307-314

13. Zeraik ML, Pereira CAM, Zuin VG, Yariwake JH (2010) Maracujá: um alimento funcional? Rev Bras Farmacogn 20:459-471

14. Domínguez-Rodríguez G, García MC, Plaza M, Marina ML (2019) Revalorization of Passiflora species peels as a sustainable source of antioxidant phenolic compounds. Sci Total Environ 696:134030

15. Jiang X, Meng Y, Liang Y, Xiao Z (2015) Evaluation of the antioxidant and antibacterial activities of various solvent extracts from Passiflora wilsonii Hemsl. Biotechnology 14:129-135

16. Song Y, Wei XQ, Li MY, Duan XW, Sun YM, Yang RL, Su XD, Huang RM, Wang $H$ (2018) Nutritional composition and antioxidant properties of the fruits of a Chinese wild Passiflora foetida. Molecules 23:1-17

17. Zeraik ML, Yariwake JH (2010) Quantification of isoorientin and total flavonoids in Passiflora edulis fruit pulp by HPLC-UV/DAD. Microchem J 96:86-91

18. Zeraik ML (2010) Estudo analítico dos flavonoides dos frutos do maracujá (Passiflora edulis Sims f. flavicarpa Degener)

19. Santos-Buelga C, Feliciano AS (2017) Flavonoids: from structure to health issues. Molecules 22:477

20. López-Vargas JH, Fernández-López J, Pérez-Álvarez JA, Viuda-Martos M (2013) Chemical, Physico-chemical, Technological, Antibacterial and 
antioxidant properties of dietary fiber powder obtained from yellow passion fruit (Passiflora edulis var. flavicarpa) co-products. Food Res Int 51:756-763

21. Zucolotto SM, Fagundes C, Reginatto FH, Ramos FA, Castellanos L, Duque C, Schenkel EP (2012) Analysis of C-glycosyl flavonoids from South American Passiflora species by HPLC-DAD and HPLC-MS. Phytochem Anal 23:232-239

22. Gadioli IL, da Cunha MD, de Carvalho MV, Costa AM, Pineli LD (2018) A systematic review on phenolic compounds in Passiflora plants: exploring biodiversity for food, nutrition, and popular medicine. Crit Rev Food Sci Nutr 58:785-807

23. Zucolotto SM, Goulart S, Montanher AB, Reginatto FH, Schenkel EP, Fröde TS (2009) Bioassay-guided isolation of anti-inflammatory C-glucosylflavones from Passiflora edulis. Planta Med 75:1221-1226

24. de Souza CG, Rodrigues THS, de Silva LMA, Ribeiro PRV, de Brito ES (2018) Sequential extraction of flavonoids and pectin from yellow passion fruit rind using pressurized solvent or ultrasound. J Sci Food Agric 98:1362-1368

25. Echeverry SM, Medina HI, Costa GM, Aragón DM (2018) Optimization of flavonoid extraction from Passiflora quadrangularis leaves with sedative activity and evaluation of its stability under stress conditions. Brazilian J Pharmacogn 28:610-617

26. Płotka-Wasylka J, Rutkowska M, Owczarek K, Tobiszewski M, Namieśnik J (2017) Extraction with environmentally friendly solvents. TrAC Trends Anal Chem 91:12-25

27. Armenta S, Garrigues S, Esteve-Turrillas FA, de la Guardia M (2019) Green extraction techniques in green analytical chemistry. TrAC Trends Anal Chem 116:248-253

28. Zuin VG, Ramin LZ (2018) Green and sustainable separation of natura products from agro-industrial waste: challenges, potentialities, and perspectives on emerging approaches. Top Curr Chem. https://doi. org/10.1007/s41061-017-0182-z

29. Fidalgo A, Ciriminna R, Carnaroglio D, Tamburino A, Cravotto G, Grillo G, Ilharco LM, Pagliaro M (2016) Eco-friendly extraction of pectin and essential oils from orange and lemon peels. ACS Sustain Chem Eng 4:2243-2251

30. Vinatoru M, Mason TJ, Calinescu I (2017) Ultrasonically Assisted Extraction (UAE) and Microwave Assisted Extraction (MAE) of functional compounds from plant materials. TrAC Trends Anal Chem 97:159-178

31. Xu D, Zheng J, Zhou Y, Li Y, Li S, Li H (2017) Ultrasound-assisted extraction of natural antioxidants from the flower of Limonium sinuatum: optimization and comparison with conventional methods. Food Chem 217:552-559

32. Taleuzzaman M, Ali S, Gilani S, Imam Hafeez A (2015) Ultra performance liquid chromatography (UPLC) - a review. Austin J Anal Pharm Chem 2:1056

33. Tufvesson LM, Tufvesson P, Woodley JM, Borhesson P (2013) Life cycle assessment in green chemistry: overview of key parameters and methodological concerns. Int J Life Cycle Assess 18:431-444

34. National Environmental Methods Index (NEMI). https://www.nemi.gov/ home/

35. Gałuszka A, Migaszewski ZM, Konieczka P, Namieśnik J (2012) Analytical Eco-Scale for assessing the greenness of analytical procedures. TrAC Trends Anal Chem 37:61-72
36. Płotka-Wasylka J (2018) A new tool for the evaluation of the analytical procedure: green analytical procedure index. Talanta 181:204-209

37. Moltesen A, Bjørn A (2018) LCA and Sustainability. In: Hauschild MZ, Rosenbaum RK, Olsen SI (eds) Life cycle assess. Theory pract. Springer International Publishing, Cham, pp 43-55

38. Turner C (2013) Sustainable analytical chemistry-more than just being green. Pure Appl Chem 85:2217-2229

39. Zuin VG, Segatto ML, Zanotti K (2020) Towards a green and sustainable fruit waste valorisation model in Brazil: optimisation of homogenizerassisted extraction of bioactive compounds from mango waste using a response surface methodology. Pure Appl Chem 92:617-629

40. Lenardão EJ, Freitag RA, Dabdoub MJ, Ferreira Batista AC, Da Cruz Silveira C (2003) "Green chemistry" - Os 12 princípios da química verde e sua inserção nas atividades de ensino e pesquisa. Quim Nova 26:123-129

41. ICH (2005) Validation of analytical procedures: text and methodology Q2 (R1). Int Conf Harmon 1994:17

42. Gil M, Restrepo A, Millán L, Alzate L, Rojano B (2014) Microencapsulation of banana passion fruit (Passiflora tripartita Var. Mollissima): a new alternative as a natural additive as antioxidant. Food Nutr Sci 05:671-682

43. Xu W-J, Zhai J-W, Cui Q, Liu J-Z, Luo M, Fu Y-J, Zu Y-G (2016) Ultra-turrax based ultrasound-assisted extraction of five organic acids from honeysuckle (Lonicera japonica Thunb.) and optimization of extraction process. Sep Purif Technol 166:73-82

44. Kähkönen MP, Hopia Al, Vuorela HJ, Rauha J-P, Pihlaja K, Kujala TS, Heinonen M (1999) Antioxidant activity of plant extracts containing phenolic compounds. J Agric Food Chem 47:3954-3962

45. Garcia-castello EM, Rodriguez-lopez AD, Mayor L, Ballesteros R, Conidi C, Cassano A (2015) Optimization of conventional and ultrasound assisted extraction of fl avonoids from grapefruit (Citrus paradisi L.) solid wastes. LWT Food Sci Technol 64:1114-1122

46. Rotta EM, Da Silva MC, Maldaner L, Visentainer JV (2018) Ultrasoundassisted saponification coupled with gas chromatography-flame ionization detection for the determination of phytosterols from passion fruit seed oil. J Braz Chem Soc 29:579-586

47. Zhang F, Yang Y, Su P, Guo Z (2009) Microwave-assisted extraction of rutin and quercetin from the stalks of Euonymus alatus (Thunb.) Sieb. Phytochem Anal 20:33-37

48. Zuin VG, Stahl AM, Zanotti K, Segatto ML (2020) Green and sustainable chemistry in Latin America: which type of research is going on? And for what? Curr Opin Green Sustain Chem 25:1-8

49. Zuin VG, Ramin LZ, Segatto ML, Stahl AM, Zanotti K, Forim MR, Silva MFF, Fernandes JB (2020) To separate or not to separate: what is necessary and enough for a green and sustainable extraction of bioactive compounds from Brazilian citrus waste. Pure Appl Chem 92:1-14

\section{Publisher's Note}

Springer Nature remains neutral with regard to jurisdictional claims in published maps and institutional affiliations.

Ready to submit your research? Choose BMC and benefit from:

- fast, convenient online submission

- thorough peer review by experienced researchers in your field

- rapid publication on acceptance

- support for research data, including large and complex data types

- gold Open Access which fosters wider collaboration and increased citations

- maximum visibility for your research: over $100 \mathrm{M}$ website views per year

At BMC, research is always in progress.

Learn more biomedcentral.com/submissions 